\title{
Jean Bodin: as Premissas DE UM EsTADO SOBERANO
}

\section{Sylvia Ewel Lenz ${ }^{1}$}

Bodin refaz o caminho de Aristóteles a Maquiavel, ao tratar das diversas formas de governo, e de como se desenvolveram e decairam [...] Também apresenta uma relação criteriosa das hierarquias do poder em um Estado Soberano. Esta ordem coercitiva se daria a partir de uma relação vertical: Deus no topo, o soberano na terra com autoridade de legislar, os magistrados agindo em seu nome para exercer o poder coercitivo sobre súditos.

K.M. BAKER

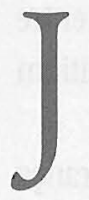

ean Bodin (c.1530-1596) iniciou a sua formação na Teologia, passando, em seguida, ao estudo do Direito, concluído em Paris. Ambos estudos, junto com o exercício da profissão de advogado no Parlamento francês, levaram-no a aplicar a teoria escolástica à experiência política. Assim, formação jurídica e atividade política permeiam assuas obras, desde as teóricas às de cunho histórico. ${ }^{2} \mathrm{Como}$ Maquiavel, ${ }^{3}$ ele não só refletia sobre questões de sua época - desavenças políticas e dissidências religiosas -, como também apresentava propostas práticas para consolidaremanter a ordem política. Oflorentino, de formação humanística, pretendeu, a partir de leituras dos escritos dos antigos, mescladas à sua experiência nas atividades políticase diplomáticas, escrever uma orientação para os dirigentes políticos. Como recorda Skinner, "Séculos antes, já era esse o objetivo da tradição de livros de aconselhamento apresentados aospodestà e aos magistrados urbanos, e essa tradição, por sua vez, seenraizava na idéia ainda mais antiga de seestenderum "espelho" aos príncipes, oferecendolhes dessa forma uma imagem ideal e pedindo-lhes que nela procurassem divisar o seu reflexo". 4

Doutora em História pela Universidade Federal Fluminense. Professora do Depto. de História da Universidade Estadual de Londrina. É autora do livro Francesco Guicciardini: o Renascimento da História. Editora da UEL.

2 Cf. Denzer, H.; MaIer, H.; Rusuch, H. Klassiker des politischen Denkens - von Plato bis Hobbes. München: C. H. Beck, 1968. p. 322.

3 Cf. Maquinvel, N. o Príncipe. Rio de Janeiro: Civilização Brasileira, 1976.

4 SkINNER, Q. As fundações do pensamento político moderno. São Paulo: Companhia das Letras, 1996. p. 139. 
Humanista, Bodin também buscou soluções para as querelas religiosas entre católicos e huguenotes, cujos eventos testemunhara e dos quais quase se tornara vítima. Os estudos jurídicos - seus empreendimentos metódicos acerca do Direito e da História -, levaram-no a defender a ordem jurídica como baluarte do Estado soberano, centrado na supremacia real, para além dos poderes imperial e papal. ${ }^{5}$ Bodin parte do princípio racional implícito em 0 Príncipe de Maquiavel, ou seja, de um Estado ordenado e ordenador, laico, acima das questões religiosas. Não obstante, temia tanto pelos exageros que um tirano poderia cometer, como pelo poder que Maquiavel delegava ao povo. ${ }^{6}$ Neste sentido, desconfiava de suas propostas, reflexo de uma nação caótica, como dos calvinistas, adeptos da tese de que o dirigente tem limites e deve satisfação aos seus súditos e cidadãos. Bodin se sobressai em construções racionais, apresentando um caminho metodológico para a elaboração de um saber político em Método para a fácil compreensão da bistória, de 1566, ganhando reconhecimento notório. Segundo a afirmação de Skinner, “....Bodin alinhou desde reflexões gerais acerca das relações entre costumes e clima, o ritmo de ascensão e queda dos estados e a disposição das estrelas, e a correspondência entre diferentes cronologias e a exegese bíblica, até simples regras empíricas que permitiam a um estudioso descobrir preconceitos num autor"?

Esta obra foi resultado das reflexões teóricas acerca do Estado a partir da herança do humanismo e do direito romano concomitante à sua atuação profissional como advogado e servidor do Estado. Neste sentido, ele apresenta as suas reflexões metodológicas acerca da História para, a partir desta obra, elaborar uma jurisprudência universal que servisse de modelo para homens pragmáticos. Bodin formulou um conhecimento jurídicopolítico no qual interligava questões teóricas, práticas políticas, administrativas e constitucionais devidamente relacionadas à economia política ${ }^{8} 0$ acadêmico em Direito, para fundamentar a história humana, deveria: “.... captar a natureza da justiça, não sujeita a mudança conforme os desejos dos homens, mas estabelecida pela lei eterna [...] aproximar e comparar a estrutura legal de todos os Estados, ou dos mais famosos Estados, e daí compilar o melhor tipo".?

Bodin empregou o método comparativo das leis e regras entre os povos, para

Denzer, H. (et. al.). Op. cit., p. 334.

6 Cf. prefácio feito para a tradução alemã dos Seis Livros de Jean Bodin - Über den Staat. Stuttgart: Philipp Reclam, 1987.

SkinNer, Q. Op. cit., p. 497.

8 Denzer, H. (et. al.). Op. cit., p. 325.

9 HADDock, B. A. Uma introdução ao pensamento bistórico. Lisboa: Gradiva, 1989. p. 62. 
chegar a um suposto direito universal, baseado no direito romano, em contraposição ao direito consuetudinário dos calvinistas. Ele já pressupunha que a história política da formação estatal só era viável se o direito estivesse relacionado à regulamentação deste Estado. ${ }^{10}$ Bodin fundamentou o saber em duas vertentes: a universalidade dos princípios gerais, sistematizada no Direito Romano; e a realidade dos eventos, da razão e da experiência histórica. Bodin dividiu a história em humana, natural e divina. Mas, como esta última não seria perceptível ao ser humano, enfatizou o saber do passado baseado no direito e na experiência histórica. Ao analisar a obra histórica de Bodin o historiador inglês B.A. Haddock observa que,

'na história, a melhor parte do direito universal acha-se escondida', enterrada em obscuros estatutos e ponderosos comentários, e é apenas quando o direito é visto em relação a uma teoria geral de 'o costume dos povos e os começos, crescimento, condições, mudanças, e decadência de todos os estados' que diferentes sistemas de direito podem ser convenientemente avaliados. ${ }^{11}$

Bodin se distancia da tradição escatológica ao conceber a história universal pelo ângulo da ascensão e queda das culturas. Desta feita, os povos das três zonas climáticas contribuíram, cada qual, para o desenvolvimento da humanidade: os povos do Oriente promoveram a cosmologia, a religião e a filosofia; os gregos e os romanos desenvolveram o Estado e a ordem jurídica e os povos do Norte europeu contribuíram com as ciências bélicas e as artes mecânicas. ${ }^{12}$

Preocupado com as sucessivas crises econômicas, Bodin, também analisa os problemas coevos, conforme atesta A Resposta a M. de Malestroit, de 1568. Aqui, Bodin superou os letrados contemporâneos, ao perceber a revolução econômica que estava em andamento ao longo do século XVI. Um reflexo de alguém que vivia em meio a carestia e mudanças na estrutura da economia européia acrescida da inflação decorrente da entrada dos metais vindos da América espanhola. 0 autor compreendeu a importância e a gravidade das finanças, recorrendo a um notável rigor lógico è ênfase de uma burocracia fiscal para a economia mercantil de um Estado forte.

Todavia, além destas obras e de sua obra magna, discutida a seguir, Bodin encerrou a sua produção intelectual, vinte anos mais tarde, quando as tensões após as guerras

\footnotetext{
${ }^{10}$ Denzer, H. (et. al.). Op. cit., pp. 334 s.

${ }^{11}$ HadDock, B. A. Op. cit., p. 63.

${ }^{12}$ Denzer, H. (et. al.). Op. cit., pp. 336 s.
} 
religiosas haviam-se acirrado, escrevendo Demonomania dos Feiticeiros, considerado o primeiro manual francês de caça às bruxas. Uma guinada surpreendente, considerando a elaboração de obras racionais, baseadas no Direito e na observação dos fatos políticos, sociais e econômicos. Pode-se elencar três motivações que o levaram a encerrar sua carreira com esta obra. A primeira, de caráter defensivo, considerando o acirramento das perseguições religiosas, levou Bodin a se redimir perante a Igreja Católica debelando-se contra o satanismo, posto que, anos antes, pertencera à facção dos Politiques, a favor da tolerância religiosa. A seguinte demonstra que, apesar de procurar desenvolver um pensamento racional, Bodin nem por isto deixa de ser crítico e crédulo ao mesmo tempo, estando impregnado da atmosfera religiosa e mágica do quinhentismo, sendo um produto do seu tempo. A última, considerando que magia e feitiçaria significavam o controle sobre forças naturais a partir de técnicas irracionais, levadas a cabo por indivíduos, portanto, fora do controle e da ordem vigente, e representavam uma ameaça ao seu idealizado Estado de Direito. ${ }^{13}$

Antes, no auge de sua carreira, as guerras religiosas entre católicos e huguenotes eclodiram na França a partir de 1562. Estes conflitos confessionais também serviam aos interesses políticos centrais, em oposição aos provinciais. Em Paris, Bodin quase foi uma das vítimas desses conflitos, na noite de São Bartolomeu, em 24 de agosto 1572, posto que integrava o grupo Politique. Este grupo defendia uma política secular, independente das influências das igrejas, reformadas ou católicas, constituindo, desta forma, as bases do Estado Moderno laico ${ }^{14} 0$ chanceler Michel de l'Hôpital, um de seus precursores, não considerava a unidade religiosa essencial para o bem-estar da França: "A imposição da uniformidade 'pode ser boa em si mesma', mas 'a experiência revelou ser impossível pô-la em prática. Tudo o que ela faz é pôr em perigo a paz, em nome da unidade religiosa, enquanto a única política racional consiste em abandonar a busca da unidade em favor da paz"." ${ }^{15}$

Desta feita, Bodin elaborou Os seis livros da República ${ }^{16} \mathrm{em}$ meio a disputas teológicas, interesses políticos e o derramamento de sangue das guerras religiosas. Ele

${ }^{13}$ Cf. os livros de Jean Delumeau, A civilização do Renascimento. Lisboa: Estampa, 1984; e de Keith Thomas, Religião e o declinio da magia. São Paulo: Companhia das Letras, 1991.

${ }^{14}$ Cf. Skinner, Q. Op. cit., p. 139.

${ }^{15}$ Id. ib., p. 523. Assim, o chanceler de Catarina de Médici encarnava as tendências conciliadoras junto com grande parte do aparelho estatal e judiciário francês do qual Bodin fazia parte.

${ }^{16} 0$ termo poderia ser usado para uma forma de governo, mas também significava as políticas de principados e reinos. 0 "Estado", como comunidade política que proclama sua soberania e o exercício da autoridade sobre dado território e sua população, não foi empregado até meados do século XVI. Aqui o utilizamos no sentido do bem público em oposição aos interesses privados. 
escreveu em francês para ter a sua obra melhor difundida entre os dirigentes de seu país. Afinal, pretendia tanto resolver os impasses das guerras religiosas e civis no reino da França como fundamentar os Estados monárquicos hereditários. Ele também pretendia que sua obra se tornasse acessível aos leigos católicos, para servir de contra-ofensiva aos monarcômanos protestantes, cuja intenção era limitar o poder do rei mediante a convocação de parlamentos, estados gerais e conselhos:

Foi o medo da anarquia, consequiência necessária, segundo ele, da doutrina de resistência legítima dos 'monarcômanos', que incitou Bodin a sustentar que, para preservar a ordem social, cumpria que se exercesse uma vontade soberana suprema. Para ser soberana, afirmava ele, essa vontade deve necessariamente ser unitária. E para ser unitária impõe-se necessariamente que seja perpétua, indivisível (portanto, inalienável) e absoluta; em conseqüência independente do julgamento ou do comando de outrem ..."17

Com esta obra sistemática, racional e baseada na justificação da soberania e da obediência às leis, Bodin publicou um dos últimos espelhos de príncipes, visando orientá-los na manutenção da ordem em prol do desenvolvimento econômico do Estado. Bodin elaborou a sua obra magna em seis livros, divididos em capítulos e editados em livro de grande porte, encadernado em couro. ${ }^{18} \mathrm{~A}$ divisão da obra obedece à seguinte organização temática:

I - Definição de conceitos e as funções da república, famílias, autoridade, cidadão, súdito, estrangeiro etc.

II - Das formas de governo - monarquia, aristocracia e democracia.

III- Dos funcionários do governo hierárquico.

IV - Auges e decadências das Repúblicas.

V- Demografia, riqueza e pobreza, caridade, punições, segurança internae externa.

VI- Finanças e apologia à monarquia soberana.

${ }_{17}$ BaKER, K. M. Soberania. In: FuRET, F. Dicionário crítico da Revolução Francesa. Rio de Janeiro: Nova Fronteira, 1989. p. 882.

${ }^{18}$ Disponíveis na Seção de Obras, da Biblioteca Nacional, onde há duas edições quinhentistas, uma em francês e a outra em espanhol, devidamente censurada segundo os ditames da inquisição espanhola: Bodin Angevin, Iean. Les six livres de la Republique. Lyon, Par Jacque du Puya, 1580 e Bodin, J.. Los seis libros de la Republica. Genève. Gabriel Cartier, 1590. São obras danificadas pela ação do tempo, com uma grafia rebuscada, tardiamente renascentista e, por si mesmas, belíssimas. 
No prefácio, o autor se refere a Maquiavel como ateu e inculto, reflexo da Itália de seu tempo. Ele lembra, também, haver poucas obras políticas. A Politica, de Aristóteles, e a República, de Platão, apesar de serem obras clássicas, prescindiam de uma fundamentação jurídica. 0 autor tinha em vista relevar a obediência à lei, portanto, ao rei, com a conseqüente observação da lei divina e o desenvolvimento humanista dos súditos. A tradução em latim logo foi publicada, tornando-se acessível aos principais dirigentes europeus. Erudita e com abordagem ampla, pretendia um saber universal, dentro da tradição renascentista. Zeloso com termos tais como república, família, magistrados, Bodin denota a influência aristotélica na elaboração acurada e lógica do pensamento. Os seis livros da República giram em torno da definição jurídica de Soberania, cujos alicerces, baseados na justiça, respaldavam-se no direito natural e divino do rei. Quentin Skinner ressalta a apresentação de suas fundamentações em defesa de uma monarquia absolutista, tendo em vista a ordem, a paz e a unidade francesa:

Abandonando a posição constitucionalista que adotara ao escrever seu Método para a fácil compreensão da bistória, Bodin revela-se, nos Seis livros, um defensor praticamente irredutível do absolutismo, exigindo que sejam proscritas todas as teorias que defendiam a resistência e se aceite, como único meio para restaurar a unidade e a paz política, uma monarquia forte. [...] Bodin claramente julgou que sua principal tarefa ideológica, nos Seis livros, consistia em atacar e refutar a teoria da resistência dos huguenotes, que passara a considerar a maior ameaça isolada à possibilidade de se restabelecer uma monarquia bem organizada na França. ${ }^{19}$

Bodin considerava que a economia francesa estava sendo prejudicada por guerras religiosas e querelas confessionais, levando o país à instabilidade. A conjuntura complexa de sua época reflete-se no texto, detalhado, denso, prolixo e longo, destacando os temas básicos tratados pelo autor, que vão da organização social da família à estrutura estatal: a) a base da sociedade é a família, cujo patriarca concentra o poder no âmbito do privado; a partir dela se reflete toda a condução da sociedade; b) um Estado monárquico baseado no poder absoluto do soberano, que estaria acima do Papado e do Império, assim como de quaisquer religiões. 0 soberano se atém à ética cristã, posto que presta contas a Deus, único Senhor acima dele; também devia seguir os princípios legais do direito natural a liberdade de viver e de possuir, ou seja, à vida e à propriedade privada; c) seguindo os passos de Maquiavel, Bodin enfatiza o poder soberano e absoluto do Príncipe; não obstante,

${ }^{19}$ SkINNER, Q. Op. cit., p. 556. 
este só pode ser hereditário, legal, oriundo de uma dada linhagem aristocrática; d) em decorrência desta premissa, o autor enfatiza o dever da obediência dos súditos, independentemente de serem nobres, clérigos, magistrados, burgueses, ou ainda, arraiamiúda; e) todos estes requisitos visam manter a ordem e a paz, possibilitando o pleno desenvolvimento da economia do Estado, de modo que este também tenha como arrecadar, manter a corte e, principalmente, garantir os custos com a manutenção de um exército permanente; f) neste sentido, Bodin inova ao destacar o papel da economia e, portanto, da coleta fiscal, e não só da força militar, para a sustentação da forma de governo entendida como uma monarquia absoluta; g) em decorrência desses argumentos, ele ressalta o papel do direito natural de cada indivíduo, isto é, o direito de viver e haver, e do direito divino, cuja ética cristã parece-nos retirada do Antigo Testamento, com um Deuspai que pune quem o desobedece. Estes sete mandamentos respaldam a obra, escrita num estilo rebuscado, complexo, quase enfadonho.

Há uma lógica que abrange a sociedade desde a sua célula nuclear à preocupação com a consolidação da ordem e da observância das leis, de modo a garantir o devido desenvolvimento econômico de sua República. Embora empregue o conceito de Etát, 0 Estado conforme concebido hoje, ${ }^{20}$ na prática, Bodin procura apresentar as condições para a existência e consolidação do mesmo, a partir de uma mescla entre o direito romano e a ética judaico-cristã de obediência ao representante supremo do poder. Como jurista, Bodin entendia que um Estado politicamente forte estava baseado em leis bem ordenadas, a serem mantidas e obedientemente seguidas.

Bodin inicia o primeiro livro definindo categorias gerais: família, soberania e Estado e elaborando uma tipologia hierarquizada dos grupos sociais, da esfera privada à pública. Ele também diferencia cidadãos de súditos e classifica os estrangeiros, tendo em vista as migrações que se davam, principalmente, entre a França e a Espanha. A família seria a fonte verdadeira e a origem do Estado: se for bem regida sob a autoridade patriarcal ela representa 0 Estado, correspondendo 0 poder doméstico ao poder soberano. Assim, continua Bodin, um bom governo doméstico serve de espelho para o governo estatal. 0 Bodin economista vinculou 0 direito de família à propriedade privada, ambos devendo ser respeitados pelo Estado. Para ele, o público só existe em oposição ao privado, i.e., à propriedade privada no âmbito civil. Os grupos de família constituem, por sua vez, as comunidades e as diversas corporações, que vivem segundo as leis da natureza visando uma convivência harmoniosa, em função da felicidade individual norteada por paixões e desejos.

${ }^{20}$ No sentido do bem comum, da coisa pública, da riqueza pública. 
Junto aos colégios, compostos por mais de três homens, formam o corpo do Estado, metáfora recorrente na Renascença e mesmo posteriormente, em Thomas Hobbes. ${ }^{21}$

Quando o patriarca deixa a esfera privada da família e vai ao mercado tratar de interesses públicos, então ele deixa de ser senhor para se tornar cidadão - citoyen -, que nada mais é do que um súdito livre - franc subiect - sujeito ao poder soberano de outrem. Mulheres e crianças estão livres da servidão, embora sujeitas à autoridade doméstica quanto a direitos, liberdade e disponibilidade, inclusive dos seus bens. Um cidadão passa a ser súdito quando tem sua liberdade limitada por aquele a quem deve obediência. Nem todo súdito é cidadão, como os escravos, por exemplo. 0 mesmo se passa com o estrangeiro, que não é cidadão por não dispor de direitos e privilégios da burguesia. Abaixo dos cidadãos há nativos e naturalizados. Os primeiros são súditos livres de um Estado em que nasceram, onde ao menos um dos pais é cidadão. 0 naturalizado se sujeita à soberania de outro sendo admitido pelo soberano como súdito. Muitos cidadãos, nativos, libertos ou naturalizados, compõem um Estado quando eles são regidos por um ou mais poderes soberanos, mesmo se houver diferenças nas leis, idiomas, costumes, religiões e nações. ${ }^{22}$

Segundo Bodin, quando todos os cidadãos são regidos pelas mesmas leis e costumes, trata-se de uma comunidade cívica, a civitas, mesmo se a população estiver espalhada em cidades, aldeias ou províncias. Um Estado não se constituirá numa comunidade civil caso não esteja sob o domínio de um soberano, da mesma forma como uma unidade doméstica não comporá uma família caso seus membros não estejam sujeitos a um chefe de família. Assim, ele pode abarcar várias comunidades civis e províncias cujos costumes se diferenciem, mas que se sujeitem à ordem de um único soberano e de suas leis. ${ }^{23}$

Os magistrados compunham uma categoria de funcionários judiciários com um poder bem mais amplo do que os juízes atuais. Eles representavam os instrumentos diretos do monarca e cuja função consistia em fazer cumprir as suas ordens, sendo praticantes da lei divina e natural no cotidiano dos súditos. Por meio deles a lei deixava de ser teoria, para ser racionalmente aplicada, provando a sua função e eficácia e, deste modo, também confirmando o poder soberano. Estas comunidades que se encontram unidas sob um poder soberano formam o Estado ou a República, conceito coevo, que

\footnotetext{
${ }^{21} O$ frontispício original de sua obra 0 Leviatã, expressa visualmente esta idéia: consta de um tórax composto de inúmeras pessoas, os súditos, mas cuja cabeça representa a fisionomia do monarca, ou seja, simboliza a razão do Estado. Cf. Hobbes. São Paulo: Abril Cultural, 1974.

${ }^{22}$ Cf. Bodin, J. Op. cit., 1987.p. 15.

${ }^{23}$ Cf. Bodin. Id. ib., p. 16.
} 
representava o domínio da esfera pública em oposição à privada, ao convívio doméstico. Aqui, Bodin vai além de teorias acerca da organização política, apresentando soluções práticas. Ele defende a sociedade civil baseada numa legislação racionalmente aplicada, diferentemente das hordas de piratas e dos bandos de ladrões, cujos acordos orais flutuam conforme os interesses do chefe vigente. A palavra de um soberano, ou seja, a lei que ele proclama aos súditos, teria a força de uma mensagem divina. Entretanto, um Estado soberano é composto de súditos, soberania e leis naturais e divinas para atender a três realizações básicas. Bodin explicita, já no capítulo inicial do primeiro livro que um Estado só éeficiente se atender a três aspectos básicos, fundamentais para a sua consolidação: as necessidades materiais, mentais e espirituais intrínsecas ao ser humano. ${ }^{24}$

Os aspectos materiais implicariam na produção agrícola e na questão demográfica, do comer e do vestir; em elementos naturais, como climáticos, hídricos e minerais e, encerrando, em estratégias defensivas e bélicas. Assim, segundo Bodin, o Estado deve ser reconhecido pelo seu território, grande e fértil o suficiente para nutrir e vestir o seu povo; ter um clima ameno, boas fontes de água e metais para fomentar a produção bélica em benefício da defesa estatal, acrescida de fortificações e de limites naturais que demarquem as fronteiras políticas. Uma vez satisfeitas as necessidades vitais, o Estado deve suprir a população no âmbito dos aspectos mentais, zelando pela formação intelectual. Assim, os indivíduos devem receber a devida formação moral, científica e filosófica acerca da natureza e de Deus, de modo a desenvolver virtudes e saber reconhecer o belo em meio à diversidade natural. Já os aspectos mentais e espirituais só podem ser alcançados após cumpridas as necessidades materiais básicas dos súditos, que devem vislumbrar Deus, a última etapa para alcançar a felicidade humana. Assim, 0 Estado deve prover as necessidades materiais, morais, científicas e culturais dos homens e, talvez, as espirituais e divinas de sua alma, de modo a que alcancem a Divindade, ponto supremo do desenvolvimento do ser humano.

Para realizar estes empreendimentos materiais e ideais, o soberano deve garantir a ordem mais do que a liberdade; todo ato de resistência de um súdito ao seu governante deveria ser proscrito em prol do interesse de preservar a frágil estrutura do governo. Logo, a sociedade política deve ter um soberano absoluto, que comande sem nunca receber ordens, jamais podendo ser legitimamente combatido pelos súditos. Tal se deve à opinião contrária de Bodin frente ao movimento huguenote, cuja essência consiste em que 
.... os magistrados e representantes do povo têm o direito moral de resistir pela força a um governo tirânico, e esse direito fundamenta-se num direito prévio e natural do povo soberano a considerar a república um meio de assegurar e aprimorar seu bem. [...] Após 1572, a principal tarefa dos revolucionários passou a ser conclamar às armas os líderes naturais do povo. Nessas circunstâncias, afirmar que tinham 0 direito de resistir significava apenas argumentar que, em termos morais, não precisavam ter receio de lutar. Mas enunciar a mesma idéia dizendo que tinham 0 dever de resistir implicava a afirmação - bem mais eloqüente -, de que eles não podiam eximir-se de tomar armas. ${ }^{25}$

As diferenças confessionais ganhavam, desta feita, um cunho político, culminando com as guerras entre os principados protestantes e o império Habsburgo, no início do Seiscentos. Diante da preocupação com a economia mercantil Bodin defendeu, acima das querelas religiosas e, portanto, políticas, a manutenção da paz e da ordem, sem as quais não haveria prosperidade material e, por conseqüência, a devida arrecadação que, por sua vez, oferecia sustentáculos ao Estado soberano. 0 conceito central na obra de Bodin é a soberania, conforme o autor o define no décimo capítulo do Livro Primeiro: significa o exercício da autoridade, de modo que o Estado disponha de um poder soberano sobre as famílias caracterizando-se por ser absoluto, vitalício, único epessoal. Antecipandose à tese do direito divino dos reis, defendida mais tarde por Bossuet, Bodin conclamou que, acima do soberano, somente o poder de Deus é superior. A soberania, na prática, significava o poder de legislar, enquanto os magistrados zelavam pela aplicação da lei, representando o exercício pragmático do mando.

Esta éuma forma de soberania fundamentada juridicamente para dar sustentação ao poder do soberano; baseia-se, portanto, no poder legislativo do soberano, a partir das leis divina, natural e consuetudinária. Estas são recebidas do poder emanado por Deus e postas em prática pelos magistrados, que representam os agentes do rei, simbolicamente, as mãos do corpo estatal. Embora discretamente, Bodin é um herdeiro constitucionalista, posto que constrói sua hierarquia judiciária a partir dos costumes e das leis naturais e divinas. Bodin entende o bom rei como aquele que é temeroso a Deus e seus súditos como obedientes ao soberano, mostrando-se envolvido em uma religiosidade cristã transconfessional. Segundo esta premissa, os atributos do soberano estão fundamentados no poder de legislar, sendo que todo o restante é decorrente deste pressuposto. Desta forma, a aplicação da Lei, no sentido mais amplo, indica a necessidade de definir os direitos de

${ }^{25}$ SKINNER, Q. Op. cit., p. 558. 
soberania que, relacionados por Bodin, são: decidir sobre a guerra e a paz que definem a queda ou segurança do Estado; nomear e exonerar funcionários do alto escalão; o direito de decisão sobre a última instância; conceder perdão aos condenados; da lealdade de súditos e vassalos; decretar o valor da moeda e do câmbio; regular pesos e medidas e tributar impostos e alfândegas. ${ }^{26}$

Em princípio, o soberano só tem, perante a nação, direitos de legislar, posto que seu único dever é para com Deus. A base do seu poder é a legislação, no que concerne à ordem pública na defesa da soberania nacional em relação aos demais Estados. Domesticamente, delega poderes e detém o controle direto sobre os funcionários, que colocam em prática a soberania interna. Exércitos efetivos e o pagamento de funcionários judiciais - os magistrados - significam altos custos para o Estado e requerem uma tributação regular sobre os súditos e a taxação de produtos importados, antecedendo as políticas econômicas do mercantilismo. Além disso, Bodin adentra-se o no âmbito do direito privado, do poder direto em decidir sobre a concessão de perdão, da exigência de lealdade dos governadose, principalmente, fornecer as bases devidas para uma a economia próspera a partir de uma regulamentação financeirae do estabelecimentos de normas de medição. Desta forma, o soberano, acima da lei, somente abaixo de Deus, é único, vitalício e hereditário, exerce um poder absoluto; só haveria eleições se uma dinastia não deixasse sucessores. Assim, embora Bodin discordasse, no oitavo capítulo do Livro Primeiro, que trata dos governos tirânicos, ele aceitava que caso tal situação viesse a ocorrer, os súditos deveriam suportar a tirania, como forma de expiar os seus pecados. ${ }^{27}$

Bebendo na fonte maquiaveliana, Bodin defendeu o poder coercitivo, incrementando a noção do Estado racional, desencadeada pelo historiador de Florença. Mas, enquanto para este tal se concretizaria no poder militar, para 0 jurista francês a coerção se aplicaria com a lei, por meio dos magistrados que podem, e do soberano, que ordena, até mesmo a pena de morte. Diferentemente de Maquiavel, valorizador da ação do indivíduo, Bodin se vinculava à sociedade estamental, das ordens sociais, herança cultural do medievo, a favor da sociedade hierárquica de ordens e defensor da monarquia hereditária, por entender que, atuando em conjunto, ambas impediriam a usurpação do poder por parte de príncipes inescrupulosos.

Nos dois atributos finais do soberano - câmbios e moeda, pesos e medida,

${ }^{26}$ Cf. Bodin. Op. cit., Livro I: p. 10.

27 Poder absoluto entendido como o direito incontestável à soberania sem partilha e não, propriamente, o direito absoluto a um poder sem limites. Cf. Lopes, M.A. o político na modernidade. Moral e virtude nos espelhos de príncipes da Idade Clássica. São Paulo: Loyola, 1997. 
tributação interna e externa -, Bodin sujeita a economia à política. Ao monarca delega decisões cambiais, cunhagem de moeda, regulamentação de pesos e medidas, além da organização de leis tributárias cuja arrecadação sustentasse economicamente a ordem interna e externa da nação. 0 Livro Quinto e parte do Sexto diferem dos outros, ao tratar das finanças assim como da responsabilidade econômica do Estado, propondo uma economia mercantil cujo controle ficaria sob as mãos do governo. Bodin incluiu parte da obra anterior sobre política econômica, na qual fizera uma análise realista e pragmática dos problemas da inflação dos preços e da carestia do seu tempo.

Ele passa, então, a temas tão variados como demografia, riqueza de uns, pobreza da maioria, provimento das necessidades básicas da população. A fome deveria ser evitada posto que hordas de mendigos e bandidos eram perniciosas ao bom andamento da produção e do comércio. Bodin dá um teor político aos problemas sociais, tendo em vista que os vincula às questões da segurança do reino: alerta para que este evite a formação de uma turba de famintos e miseráveis, além de possíveis rebeliões populares. 0 autor também considera vital preservar um índice demográfico estável, sem queda populacional, tendo em vista a força econômica das pessoas produtivas para a manutenção de um Estado monárquico forte, força esta obtida pela arrecadação tributária. Em termos de defesa externa, o governo também precisaria dispor de um número de efetivos em seu exército nacional permanente. Estes são os objetivos materiais de responsabilidade do soberano, conforme já elencara no Livro Primeiro. Apesar dos preâmbulos aristotélicos voltados para aspectos intelectuais - a formação educacional e cristã, a formação espiritual dos súditos-, os capítulos seguintes carecem de uma menção proporcional a estas, como as dedicadas à alimentação e à segurança dos súditos. Os compromissos do soberano para com os súditos recordam os acordos feudais entre senhores e vassalos, em que estes trabalhavam a terra em troca da proteção daqueles. ${ }^{28}$

Embora seja um fator natural, Bodin também trabalhou a questão climática posto que esta é decisiva para uma boa produção agrícola, também voltada para 0 planejamento do plantio e do controle da armazenagem de grãos em tempos de escassez alimentar. Sob este aspecto precede Montesquieu, ao tratar de clima, mas com abordagem distinta do determinismo deste, quanto ao caráter dos habitantes de zonas quentes ${ }^{29} 0$ filósofo iluminista certamente bebeu em fontes bodinianas tais como as questões climáticas e a produção agrícola, das águas e minerais, preocupações fundamentais para

\footnotetext{
${ }^{28}$ Cf. Bodin. Op. cit., Livro V.

${ }^{29}$ Montesquieu, conforme Livro 14 - "Das leis em sua relação com a natureza do clima" na edição brasileira $O$ espirito das leis. São Paulo: Martins Fontes, 1996.
} 
a governabilidade, tendo em vista a segurança e a riqueza do país. Mas ambos visam o bom convívio entre os homens, a manutenção da ordem e da paz tendo em vista o ideal aristotélico da felicidade.

Bodin encerra a obra considerando somente três formas de governo - monarquia, democracia e aristocracia -, defendendo a primeira. Ele considera a democracia a mais perfeita forma de governo, já que visa princípios como igualdade e justiça, sem concessão de privilégios. A constituição seguiria leis naturais, já a natureza disponibilizaria suas riquezas para todos. Na democracia, todos partilhariam do bem público, dividindo propriedade, bens e conquistas, enquanto que somente alguns na aristocracia, e somente um teria este privilégio na monarquia. Entretanto, seu governo mostrar-se-ia frágil, arruinando-se devido a egoísmos, mesquinharias e indiferenças inerentes à natureza humana ${ }^{30}$ Neste sentido, o autor é contra as teorias comunais de Platão, conforme expressou no governo idealizado da República. Para Bodin, a propriedade privada é, segundo os desígnios de Deus, o fundamento material do Estado, assim como a família é a formação social, a obediência, o comportamento ético, e a soberania, o seu esteio político. Mas, como são raras as pessoas instruídas, havendo muitos que agem como animais, a democracia beiraria à irracionalidade, favorecendo o comportamento tirânico dos poucos capazes de governar.

A aristocracia representa 0 governo dos melhores, mais ricos e inteligentes, intermediária entre o governo de todos e o de um só. A sua política ideal éo consenso entre os senhores. Entretanto, podem surgir facções que a dividam e, portanto, a fragilizem. Para Bodin, há dois governos aristocráticos: o militar, herdeiro da natureza guerreira dos nobres feudais; e o comercial, de natureza pacífica, representado pela elite composta por negociantes e profissionais liberais das cidades modernas. Contudo, Bodin compara a monarquia soberana às realezas das civilizações antigas, que teriam durado por até mais de mil anos. Ele também fundamenta a sua preferência às leis naturais fazendo analogias entre Deus, que dirige o mundo, o sol, que rege o universo, a cabeça, que coordena o corpo. Ele ainda faz referências às leis civis em que o patriarca comanda a família, que é a célula do Estado.

Finalizando, apesar do compêndio de Bodin em defesa da soberania absoluta do Estado, em prol da paz geral, esta somente foi consolidada nos países da Europa com resistências e reveses. Mas Bodin propôs uma organização política visando restabelecer a ordem em uma cristandade conturbada. A ênfase de Bodin em prol do

${ }^{30} \mathrm{Cf}$. Bodin. Op. cit., Livro VI. 
poder absoluto denota uma ausência de mecanismos efetivos - fiscais, tributários, burocráticos -, que viabilizassem, de imediato, a consolidação do poder centralizador, o que se dará ao longo do século XVII. Por outro lado, houve uma ascensão social de financistas e plebeus por intermédio do poderio econômico, na compra de títulos, cargos, ou mesmo matrimôni 's de homens burgueses com mulheres da nobreza. Os valores que perpassam a obra denotam o humanismo neoplatônico, cuja finalidade moral seria 0 aprimoramento espiritual ou, ainda, resquícios de uma formação teológica. Apesar de manter um raciocínio cuidadoso e do zelo taxionômico com os conceitos, Bodin seguiu a formação escolástica que iniciava com o estudo da retórica, música, astrologia e culminava com a teologia, a rainha das ciências. Apesar da indefinição confessional de Bodin, ao assumir que o conhecimento de Deus representava a suprema felicidade, revelou uma profunda religiosidade.

0 autor seguiu também 0 ideal aristotélico, ao defender a função política do Estado, com vistas à felicidade da nação, por meio da vida civil em prol do bem comum, devidamente ordenado por uma autoridade soberana. A função do soberano, no que tange ao bem comum, visava a defesa de direitos naturais e divinos liberdade sobre a vida e a propriedade. Bodin preocupou-se com a prosperidade econômica tendo em vista que o comércio dependia da paz e da garantia de proteção legal dos contratos. Estas necessidades correspondem a um período em que a sociedade mercantil empreendida pela burguesia estava em franca ascensão, alavancada pelos metais preciosos provenientes das Américas. Desta feita, o soberano seria único e com poder absoluto perante os seus magistrados, a nobreza, o clero e o povo. 0 rei estaria acima do Papado e do Imperador, de modo a manter a ordem interna de sua nação, devendo sobrepor-se às querelas confessionais, evitando guerras religiosas em prol da paz. Esta forma de governo só seria possível tendo como instrumento básico uma ordem política devidamente hierarquizada.

Por detrás da preocupação de Bodin com uma forma perfeita de governo, há a motivação implícita pela prosperidade material, de modo a que esta possibilite a formação intelectual dos súditos. Tal realização possibilitaria o desenvolvimento espiritual do indivíduo, fim último deste longo processo, passível de ser realizado por uma estrutura estatal racional e absoluta. Bodin foi um precursor da Ilustração, pois, a partir da prática política e do conhecimento legal e justo, visava a paz, a prosperidade, a formação cultural e espiritual em função da felicidade geral. Somente uma monarquia legítima formaria um corpo político único, sólido e forte. Assim, ele seguiu a idéia do governo com um só príncipe, semelhante ao monoteísmo 
Jean Bodin: as Premissas de um Estado Soberano 133

cristão regido por um Deus perfeito, defendido na argumentação política por Dante Alighieri (1265-1321), mas acrescido do elemento jurídico. ${ }^{31}$

${ }^{31}$ Conforme o seu Livro Primeiro da obra Da monarquia, na edição portuguesa. Lisboa: Guimarães Editora, 1999. 